\title{
IMPORTANCE OF PROFESSIONAL PRACTICE IN PHARMACIST LIFE
}

\author{
Tarun Garg*, Arsh Chanana, Ankit Gupta, Neetu Khatri, Govind Sharma \\ Seth G.L.Bihani S.D. College of Technical Education, Sriganganagar
}

\section{INTRODUCTION}

Professional practice is a blueprint of good pharmacy practice. It is the foundation for all college of pharmacists. It describes the standards the college uses to assess quality of pharmacy practice, and provides the basis of current and future practice support initiatives. It supports the college's mission to ensure safe and effective pharmacy care to help the people achieve better health. Professional Practice is designed to help pharmacists enhance their practice and patient outcomes and guide their professional development.

\section{ROLES, FUNCTIONS \& ACTIVITES IN PROFESSIONAL PRACTICE}

Role 1: Provide pharmaceutical care

Function A: Assess the client's health status and needs

Activity 1: Establish and maintain a relationship with the client

Activity 2: Obtain information about the client's health

Activity 3: Determine the client's desired health outcomes and priorities

Function B: Develop a care plan with the client

Activity 1: Formulate care plan options

Activity 2: Make recommendations to meet the client's need

Activity 3: Support the client to select (a) care plan option(s)

Activity 4: Refer the client to other services

Function C: Support the client to implement the care plan

Activity 1: Enable the client to maximize health outcomes

Activity 2: Provide drug therapy and devices

Activity 3: Provide information

Function D: Support and monitor the client's progress with the care plan

Activity 1: Obtain and evaluate information on the client's progress with the care plan

Activity 2: Confirm or modify the client's care plan

Function E: Document findings, follow-ups, recommendations, information provided and client outcomes

Activity 1: Document information

Activity 2: Maintain and store information

Role 2: Produce and distribute drug preparations and products

Function A: Produce drug preparations and products

Activity 1: Prepare pharmaceutical products

Activity 2: Package pharmaceutical products

Activity 3: Create and maintain records

Function B: Store drug preparations and products

Activity 1: Maintain storage environment

Activity 2: Maintain storage system

Function C: Distribute drug preparations and products

Activity 1: Maintain security and integrity during the distribution process

Activity 2: Maintain records of distribution

Function D: Dispose of drug preparations and products

Activity 1: Identify products requiring disposal

Activity 2: Store products requiring disposal securely

Activity 3: Remove products from pharmacy for disposal

Role 3 Contribute to the effective operation of the pharmacy

Function A: Contribute to the maintenance of a productive working environment

Activity 1: Maintain physical environment

Activity 2: Contribute to the health, safety and security of the environment

Function B: Contribute to the management of human resources within the practice

Activity 1: Contribute to identifying human resource needs

Activity 2: Contribute to the development of individuals and teams 
Activity 3: Supervise staff

Activity 4: Anticipate and prepare for change

Function C: Contribute to systems to provide products and quality services

Activity 1: Contribute to management and maintenance of inventory

Activity 2: Create, maintain and improve information and resources

Activity 3: Seek continuous improvement

Function D: Contribute to the viability of the practice

Activity 1: Maximize the efficient use of resources

Activity 2: Promote and market the pharmacy practice

Function E: Minimize practice errors and omissions, unsafe practices and professional misconduct

Activity 1: Identify and prevent practice errors/omissions, unsafe practices and professional misconduct

Activity 2: Minimize, manage and report practice errors and omissions

Activity 3: Respond to and resolve unsafe practices and professional misconduct

Role 4 Maintain professional development \& contribute to the professional development of others

Function A: Plan and implement personal development strategies to improve current and future performance

Activity 1: Create and maintain a professional development plan to improve current and future performance

Activity 2: Monitor, evaluate and record development achievements

Function B: Contribute to the professional development of colleagues

Activity 1: Respond to the development needs of colleagues

Activity 2: Support development and practice enhancement initiatives

Role 5 Contribute to the effectiveness of the health care system

Function A: Promote, evaluate and improve health in the community

Activity 1: Encourage health and wellness

Activity 2: Support access to health information

Activity 3: Identify problems and solutions to improve health care in the community

Function B: Advocate and support policies that promote improved health outcomes

Activity 1: Contribute to public and professional forums to promote improved health outcomes

Activity 2: Contribute to policy direction and decisions to improve health outcomes

Activity 3: Collaborate with other health care professionals in their efforts to improve health outcomes

Function C: Create, maintain and enhance working relationships with others

Activity 1: Exchange information and advice with others

Activity 2: Contribute to health and wellness problem-solving

Function D: Contribute to the education and training of students and health professionals

Activity 1: Identify the learning needs and goals of students and health professionals

Activity 2: Select or develop learning activities to meet identified needs and goals

Activity 3: Facilitate or implement learning activities and assess outcomes

Activity 4: Evaluate quality of education and training

Function E: Contribute to the discovery of new knowledge and skills and their application to pharmacy practice and the health care system

Activity 1: Participate in client care practices that yield new or expanded knowledge about the effectiveness and safety of drugs

Activity 2: Investigate and contribute to research activities that improve health outcomes, support the health of the public and enhance pharmacy practice

\section{PHARMACIST VALUES FOR PROFESSIONAL PRACTICE}

Value 1: A pharmacist respects the professional relationship with the patient and acts with honesty, integrity and compassion.

Value 2: A pharmacist honours the individual needs, values and dignity of the patient.

Value 3: A pharmacist supports the right of the patient to make personal choices about pharmacy care.

Value 4: A pharmacists provides competent care to the patient.

Value 5: A pharmacist protects the patient's right of confidentiality.

Value 6: A pharmacist actively supports the patient's right to receive competent and ethical health care.

Value 7: A pharmacist respects the values and abilities of colleagues and other health professionals.

Value 8: A pharmacist endeavours to ensure that the practice environment contributes to safe and effective pharmacy care.

Value 9: A pharmacist ensures continuity of care in the event of job action, pharmacy closure or conflict with moral beliefs. 